\title{
Erratum to: The consequences of interactions between dispersal distance and resolution of habitat clustering for dispersal success
}

\author{
Lorenzo Cattarino - Clive A. McAlpine • \\ Jonathan R. Rhodes
}

Published online: 13 June 2013

(C) Springer Science+Business Media Dordrecht 2013

\section{Erratum to: Landscape Ecol DOI 10.1007/s10980-013-9881-1}

The original publication of the article includes an error in Eq. (2). The correct version of the equation, and consequently the wording of the whole paragraph is as follows:

The probability, $P_{i}$, of moving to cell, $i$, was

$$
P_{i}=\frac{\phi_{i} w_{j}}{\sum_{k=1}^{8} \phi_{k} w_{k}}
$$

where $\phi_{i}$ is the probability of taking a particular turning angle (i.e. by moving to cell $i$ ) in the absence of landcover preference and $w_{j}$ is the habitat preference parameter for land cover type $j$ (i.e. habitat or nonhabitat). The denominator of Eq. (2) acts as a normalizing constant and ensures the probabilities, $P_{i}$, add to one.

The online version of the original article can be found under doi:10.1007/s10980-013-9881-1.

L. Cattarino - C. A. McAlpine · J. R. Rhodes Landscape Ecology and Conservation Group, Centre for Spatial Environmental Research, School of Geography, Planning and Environmental Management, The University of Queensland, Brisbane, QLD 4072, Australia

L. Cattarino ( $\square)$

Australian Rivers Institute, Griffith University, Nathan,

QLD 4111, Australia

e-mail: 1.cattarino@griffith.edu.au 